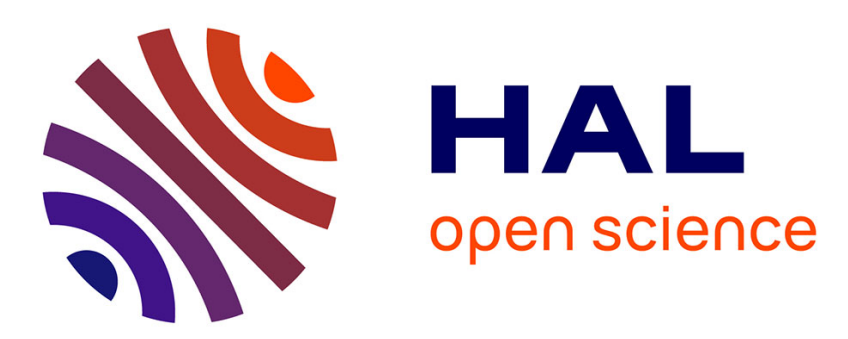

\title{
Reduced Order Modeling Approach to Combustion Instabilities of Liquid Rocket Engines
}

M. Gonzalez-Flesca, P. Scouflaire, Schmitt Thomas, S. Ducruix, S. Candel, Y. Mery

\section{- To cite this version:}

M. Gonzalez-Flesca, P. Scouflaire, Schmitt Thomas, S. Ducruix, S. Candel, et al.. Reduced Order Modeling Approach to Combustion Instabilities of Liquid Rocket Engines. AIAA Journal, 2018, pp.1 - 13. 10.2514/1.J057098 . hal-01934911

\section{HAL Id: hal-01934911 https://hal.science/hal-01934911}

Submitted on 4 Mar 2020

HAL is a multi-disciplinary open access archive for the deposit and dissemination of scientific research documents, whether they are published or not. The documents may come from teaching and research institutions in France or abroad, or from public or private research centers.
L'archive ouverte pluridisciplinaire HAL, est destinée au dépôt et à la diffusion de documents scientifiques de niveau recherche, publiés ou non, émanant des établissements d'enseignement et de recherche français ou étrangers, des laboratoires publics ou privés. 


\title{
Reduced order modeling approach to combustion instabilities of liquid rocket engines
}

\author{
M. Gonzalez-Flesca*, P. Scouflaire ${ }^{\dagger}$, T. Schmitt ${ }^{\ddagger}$, S. Ducruix ${ }^{\S}$, and S. Candel ${ }^{\mathbb{I I}}$ \\ Laboratoire EM2C, CNRS, CentraleSupélec, Université Paris-Saclay \\ 3 rue Joliot Curie, Bat. Eiffel, 91192 Gif-sur-Yvette cedex, France

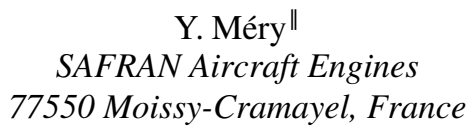

This article describes the numerical framework for a reduced order tool which aims at simulating combustion instabilities in liquid rocket engines. The numerical framework relies on the projection of the pressure fluctuations on $t$ he e igenmodes of $t$ he $s$ ystem. Pressure fluctuations are solutions of the wave equation of the system. After projection on the eigenmodes, the wave equation takes the form of series of second order harmonic equations with source terms that drive combustion instabilities and damping terms that attenuate them. A test rig was developed to study cavity interactions, injector impedance as well as damping effects. Damping rates measured on the test rig show a trend which is consistent with what is observed in liquid rocket engines. On a whole, the test rig can be used to validate simplified models of combustion instabilities. The global framework of the reduced order tool developed to predict combustion instabilities in liquid rocket engines was first validated by comparing the data from simulations against experimental results from the test rig in a series of non-reacting experiments. The tool was then used in a case study of a full-scale rocket engine. This engine, under certain operating conditions, exhibits instabilities. Stable and unstable behaviors have been revealed by the temporal evolution of pressure amplitudes.

\section{Nomenclature}

$$
\begin{aligned}
p & =\text { pressure }[\mathrm{Pa}] \\
x & =\text { position vector }[\mathrm{m}, \mathrm{m}, \mathrm{m}] \\
t & =\text { time }[\mathrm{s}]
\end{aligned}
$$

\footnotetext{
*PhD, Ingénieur ISAE-ENSMA, m.gonzalezflesca@gmail.com

†Ingénieur de recherche au CNRS, philippe.scouflaire@centralesupelec.fr

†Chargé de recherche au CNRS, thomas.schmitt@centralesupelec.fr

§ Directeur de recherche au CNRS, sebastien.ducruix@ centralesupelec.fr

"Professeur des Universités, sebastien.candel@ centralesupelec.fr

"Expert engineer at Safran Aircraft Engines,yoann.mery@ safrangroup.com
} 


$$
\begin{aligned}
& \eta_{i}=\text { pressure amplitude of the } \mathrm{i}^{\text {th }} \text { mode }[\mathrm{Pa}] \\
& \Psi_{i}=\mathrm{i}^{\text {th }} \text { modal eigenfunction } \\
& \omega_{i}=\text { angular eigenfrequency of the } \mathrm{i}^{\text {th }} \operatorname{mode}[\mathrm{Hz}] \\
& c \quad=\quad \text { sound velocity }\left[\mathrm{m} \cdot \mathrm{s}^{-1}\right] \\
& \rho \quad=\quad \text { density }\left[\mathrm{kg} \cdot \mathrm{m}^{-3}\right] \\
& \boldsymbol{u}=\text { velocity vector }\left[\mathrm{m} \cdot \mathrm{s}^{-1}, \mathrm{~m} \cdot \mathrm{s}^{-1}, \mathrm{~m} \cdot \mathrm{s}^{-1}\right] \\
& T \quad=\text { temperature }[\mathrm{K}] \\
& s \quad=\quad \text { entropy }\left[\mathrm{J} \cdot \mathrm{kg}^{-1} \cdot \mathrm{K}^{-1}\right] \\
& Q \quad=\quad \text { heat release rate per unit of volume }\left[\mathrm{J} . \mathrm{m}^{-3}\right] \\
& c_{v}=\text { specific heat of the mixture at constant volume }\left[\mathrm{J} \cdot \mathrm{kg}^{-1} \cdot \mathrm{K}^{-1}\right] \\
& \gamma \quad=\quad \text { specific heat ratio } \\
& S_{\text {comb }}=\text { combustion source term }\left[\mathrm{Pa} . \mathrm{s}^{-2}\right] \\
& S_{\text {exc }}=\text { excitation source term }\left[\mathrm{Pa}_{\mathrm{s}} \mathrm{s}^{-2}\right] \\
& \left.S_{n l}=\text { non linear effects associated to large acoustic amplitudes [Pa.s }{ }^{-2}\right] \\
& S_{d} \quad=\text { damping term }\left[\mathrm{Pa}_{\mathrm{s}} \mathrm{s}^{-2}\right] \\
& l_{i} \quad=\quad \text { length in the } i \text { direction }[\mathrm{m}] \\
& f \quad=\quad \text { frequency }[\mathrm{Hz}] \\
& R \quad=\quad \text { radius of a cylinder }[\mathrm{m}] \\
& L \quad=\quad \text { length of a cylinder }[\mathrm{m}] \\
& J_{i} \quad=\quad \text { Bessel function of order } i \text { of the first kind } \\
& \beta_{j, i} \quad=\quad \operatorname{root} \text { of } J_{i}^{\prime}\left(\pi \beta_{j, i}\right)=0 \\
& \xi=\text { head loss coefficient } \\
& \Delta P=\text { total pressure difference between the dome and the chamber }[\mathrm{Pa}] \\
& V \quad=\quad \text { voltage applied to the hot wire }[\mathrm{V}] \\
& \alpha \quad=\quad \text { damping rate }\left[\mathrm{s}^{-1}\right] \\
& \dot{m}_{i} \quad=\text { mass flow rate exiting the } \mathrm{i}^{\text {th }} \text { nozzle }\left[\mathrm{kg} . \mathrm{s}^{-1}\right] \\
& L_{f} \quad=\quad \text { length of the flame }[\mathrm{m}]
\end{aligned}
$$




\section{Introduction}

Ever since the beginning of liquid rocket-engine development in the 1950s ([1, 2]), high frequency combustion instabilities have been a big issue. The complex interactions between the combustion process inside the combustion chamber, the injection conditions of the liquid propellants and the acoustic eigenmodes of the engine may lead to self-sustained vibrations that, in some extreme cases of resonance with the structure, can cause the destruction of the engine. High frequency combustion instabilities are difficult to tackle since the interaction between combustion, injection and resonant acoustic modes is not well understood. Most of the early knowledge on high frequency combustion instabilities was achieved through trial and error as detailed in [3]. The recent expansion of the computing power has allowed to gain considerable knowledge on the fundamental mechanisms of combustion instabilities resulting in the improvement of liquid rocket-engines.

Computational fluid dynamics such as Direct Numerical Simulation (DNS) and Large Eddy Simulation (LES) have been able to give precious insights on the several mechanisms that occur in transcritical and supercritical coaxial cryogenic flames ([4, 5, 5,-11]). Phenomena such as flame anchoring, jet dynamics and flame - acoustic field interactions have provided a better understanding of the complex coupling of combustion instabilities. Numerical simulations are not the only field of activity that has been thriving for the understanding of combustion instabilities in liquid rocket engines; test rigs representing a full rocket engine ([12]), simplified rigs operating under cryogenic conditions $([13-16])$ as well as non-reacting test rigs ([17,-19]) have given visual representations of the interaction between the flame and the acoustic field. Simulation and experimentation together $([5,10,11])$, as well as theoretical work $([20])$, have demonstrated that the movement of the flame and the fluctuating pressure inside the combustion chamber can cause an increase in the heat released by a flame. Furthermore fluctuations in the injection mass flow rate can change the heat release rate of a flame. These phenomena constitute source terms of the combustion instability that drive it. These source terms are in competition with damping terms that reduce the instability. Early work from ([1, 2, 21, 22]) emphasized the importance of delays in the combustion process. This gave rise to the sensitive time lag model, developed in the 1950s ([22]).

In order to predict combustion instabilities in liquid engine, one has to understand the interactions between the combustion process, the acoustic modes of the engine and the injection conditions. Simulations and experimentation provide important information on the matter and in order to predict the instability, all the information must be gathered in a convenient format. In this work, a reduced order dynamical model is presented in order to gain knowledge on combustion instability mechanisms.

This work is organized as follows. The governing equations and the modeling assumptions of the reduced order tool are described in section II A test rig is presented in section III The measurement of the damping rates, which is a necessary parameter for the study of combustion instabilities, is proposed in section IV] The reduced order tool developed in this work is presented, and was validated in a series of non-reacting experiments, in section $\mathrm{V}$. Finally in section $\mathrm{VI}$, the reduced order tool is used on a full scale rocket engine case study. 


\section{Principles of reduced order modeling}

The objective of reduced order dynamical modeling of combustion instabilities is to provide a simplified framework for the analysis of combustion dynamics phenomena. This however requires a set of submodels for the driving and damping mechanisms intervening in this process. Only the most important phenomena are considered according to a selection based on theory, experiments and simulations. As in any other attempt to use reduced order descriptions this requires a set of assumptions that need to be validated. One advantage of reduced order modeling is that it requires far less computational resources than complex calculations relying on LES or unsteady Reynolds-Averaged Navier-Stokes (RANS) simulations. The method used in what follows was initially proposed by [23] and extensively explored by Culick and his co-workers ([24]). The principles of the reduced order framework are presented here.

The present reduced order modeling relies on a physical principle, which consists of an expansion of state variables in terms of the system eigenmodes. It is assumed that the pressure field can be written as a sum of a mean pressure and a fluctuation $p=\bar{p}+p^{\prime}$ where $\bar{p}$ is the mean pressure and $p^{\prime}$ the pressure fluctuation. The pressure fluctuations are then projected on the acoustic eigenmodes of the system:

$$
p^{\prime}(\mathbf{x}, t)=\sum_{n=0}^{N} \eta_{n}(t) \Psi_{n}(\mathbf{x})
$$

where $\eta_{n}$ is the amplitude of the $\mathrm{n}^{\text {th }}$ mode and $\Psi_{n}$ is the $\mathrm{n}^{\text {th }}$ modal eigenfunction. These eigenfunctions satisfy a boundary value problem defined by a Helmholtz equation ([25]), together with boundary conditions on the frontiers of the domain of interest.

$$
\nabla^{2} \Psi_{n}+\frac{\omega_{n}^{2}}{c^{2}} \Psi_{n}=0
$$

where $c$ is the sound velocity. Let us assume that the boundary conditions are of the Neumann or Dirichlet ([26]) or mixed type, i.e. that $\boldsymbol{n} \cdot \nabla \Psi_{n}=0$ or that $\Psi_{n}=0$.Under these conditions it is easy to show that the eigenmodes are orthogonal so that:

$$
\int_{V} \Psi_{n} \Psi_{m}=\Lambda_{n} \delta_{n m}
$$

where $\delta_{n m}=0$ when $m \neq n$ and $\delta_{n m}=1$ when $n=m$. In the previous expression $\Lambda_{n}=\int_{V} \Psi_{n}^{2} d V$ represents the integral over the domain of the square of the $n^{\text {th }}$ eigenfunction. This quantity has the dimensions of a volume $\left[\Lambda_{n}\right]=L^{3}$. One may now derive a wave equation for the pressure field. This is achieved by making use of the mass, momentum and energy equations. Under reacting flow assumptions the equations of mass, momentum and energy can be written in the 
form:

$$
\begin{array}{r}
\frac{\partial \rho}{\partial t}+\nabla \cdot \rho \boldsymbol{u}=0 \\
\rho \frac{\partial \boldsymbol{u}}{\partial t}+\rho \boldsymbol{u} \cdot \nabla \boldsymbol{u}=-\nabla p \\
\rho T\left(\frac{\partial s}{\partial t}+\boldsymbol{u} \cdot \nabla s\right)=\dot{Q} \\
p=\rho^{\gamma} e^{s / c_{v}}
\end{array}
$$

where $\rho$ is the density, $\boldsymbol{u}=\left(u_{1}, u_{2}, u_{3}\right)$ the velocity vector, $\gamma$ is the specific heat ratio, $s$ is the constant entropy of the flow, $c_{v}$ is the specific heat of the mixture at constant volume and $\dot{Q}$ is the heat release rate per unit of volume. Small perturbations of the density, pressure and velocity vector are assumed. As stated before, these variables can be written as a sum of a mean value and a fluctuation $\rho=\bar{\rho}+\rho^{\prime}, p=\bar{p}+p^{\prime}$ and $\boldsymbol{u}=\overline{\boldsymbol{u}}+\boldsymbol{u}^{\prime}$ for the density, pressure and velocity vector respectively. By inserting these expressions in equations 4 to 7 assuming that the mean flow velocity is small and only retaining the first order perturbation terms, one obtains a wave equation which takes the form:

$$
\nabla^{2} p^{\prime}-\frac{1}{c^{2}} \frac{\partial^{2} p^{\prime}}{\partial t^{2}}=-\frac{\gamma-1}{c^{2}} \frac{\partial \dot{Q}^{\prime}}{\partial t}
$$

It is convenient to first represent the right hand side of the last equation in the form

$$
h=-\frac{\gamma-1}{c^{2}} \frac{\partial \dot{Q}^{\prime}}{\partial t}
$$

so that the wave equation becomes

$$
\nabla^{2} p^{\prime}-\frac{1}{c^{2}} \frac{\partial^{2} p^{\prime}}{\partial t^{2}}=h
$$

and let us assume that the pressure field satisfies boundary conditions of the form:

$$
\boldsymbol{n} \cdot \nabla p^{\prime}=-f
$$

where $f$ is a function that is equal to zero on rigid boundaries. When this function differs from zero it defines the value of the normal velocity at the boundary. One may now multiply the wave equation (10) by $\Psi_{m}$ and the Helmholtz equation (2) by $p^{\prime}$ and subtract the second result from the first to get:

$$
\Psi_{m} \nabla^{2} p^{\prime}-p^{\prime} \nabla^{2} \Psi_{n}-\frac{1}{c^{2}} \frac{\partial^{2} p^{\prime}}{\partial t^{2}} \Psi_{m}-\frac{\omega_{n}^{2}}{c^{2}} p^{\prime} \Psi_{n}=h \Psi_{m}
$$


This equation may now be integrated over the volume of the studied domain, $V$ :

$$
\begin{array}{r}
\int_{V}\left(\Psi_{m} \nabla^{2} p^{\prime}-p^{\prime} \nabla^{2} \Psi_{n}\right) d V+\frac{1}{c^{2}} \sum_{n=1}^{N} \int_{V} \frac{d^{2} \eta_{n}}{d t^{2}} \Psi_{n} \Psi_{m} d V \\
-\frac{1}{c^{2}} \omega_{n}^{2} \sum_{n=1}^{N} \eta_{n} \int_{V} \Psi_{n} \Psi_{m} d V=\int_{V} h \Psi_{m} d V
\end{array}
$$

where the modal expansion (1) has been introduced in the last two terms of the left hand side. One may now use the Green's identity to replace the first term of the left hand side by a surface integral on the control surface of the domain $A$ :

$$
\int_{V}\left(\Psi_{m} \nabla^{2} p^{\prime}-p^{\prime} \nabla^{2} \Psi_{n}\right) d V=\int_{A}\left(\Psi_{m} \nabla p^{\prime}-p^{\prime} \nabla \Psi_{n}\right) \cdot \boldsymbol{n} d A
$$

Making use of the boundary conditions on $\Psi_{n}$ and on the pressure field one obtains:

$$
\int_{V}\left(\Psi_{m} \nabla^{2} p^{\prime}-p^{\prime} \nabla^{2} \Psi_{n}\right) d V=-\int_{A} f \Psi_{m} d A
$$

Noting that the eigenmodes are orthogonal one finds that

$$
\frac{d^{2} \eta_{n}}{d t^{2}}+\omega_{n}^{2} \eta_{n}=-\frac{c^{2}}{\Lambda_{n}}\left[\int_{V} h \Psi_{n} d V+\int_{A} f \Psi_{n} d A\right]
$$

The modal amplitudes $\eta_{n}(t)$ are determined by the previous set of coupled differential equations. Inserting the definition of $h$ in the previous equations one obtains:

$$
\frac{d^{2} \eta_{n}}{d t^{2}}+\omega_{n}^{2} \eta_{n}=\frac{\gamma-1}{\Lambda_{n}} \int_{V} \frac{\partial \dot{Q}^{\prime}}{\partial t} \Psi_{n} d V-\frac{c^{2}}{\Lambda_{n}} \int_{A} f \Psi_{n} d A
$$

The last term on the right hand side corresponds to driving or damping effects associated with boundary values of the normal pressure gradient. This term will be designated in what follows by

$$
F_{n}=-\frac{c^{2}}{\Lambda_{n}} \int_{A} f \Psi_{n} d A
$$

The damping mechanisms, that tend to reduce instabilities, are represented in a formal way by $D_{n}$ and corresponds to the damping of the $\mathrm{n}^{\text {th }}$ mode. The evolution of the modal amplitudes is defined by the following equations

$$
\ddot{\eta}_{n}(t)+\omega_{n}^{2} \eta_{n}=\frac{\gamma-1}{\Lambda_{m}} \int_{V} \frac{\partial \dot{Q}^{\prime}}{\partial t} \Psi_{m}(\mathbf{x}) d V+F_{n}-D_{n}
$$

where $\omega_{n}$ is the angular eigenfrequency of the $\mathrm{n}^{t h}$ mode, $\Lambda_{m}=\int_{V} \Psi_{m}^{2} d V$ is the norm of the $\mathrm{m}^{\text {th }}$ mode, $\dot{Q}^{\prime}$ is the 
volumetric heat release rate fluctuation (or unsteady heat release), $F_{n}$ and $D_{n}$ respectively represent effects associated with fluctuations of the normal pressure gradient at the boundaries and damping in the system. Equation 19 can be rewritten as a sum of four terms each representing a particular contribution to the total instability.

$$
\ddot{\eta}_{n}(t)+\omega_{n}^{2} \eta_{n}=S_{\text {comb }}+S_{\text {exc }}+S_{n l}-S_{d}
$$

In equation $20 S_{\text {comb }}$ represents the combustion source term (a term linked to the combustion process that may drive instabilities), $S_{e x c}$ represents an exterior excitation (a term that may also drive instabilities), $S_{n l}$ represents nonlinear effects associated to large acoustic amplitudes (a term that may limit oscillation amplitudes) and $S_{d}$ reflects damping effects in the domain (a term that may reduce instabilities). Each of these terms requires a model or models that may be based on theoretical reasoning, experimental data or simulations. It is interesting to note that a single module can carry several models in order to represent different mechanisms independent from one another. It is worth mentioning that all previous equations are for a constant sound velocity and ideal gases with constant calorimetry coefficients, which is not true in the supercritical and transcritical conditions that can be found in liquid rocket engines. However similar equations are found with an appropriate real gas sound velocity, which will be used later on in this work.

A brief review of eigenmodes and eigenfrequencies in classical cavities such as rectangular and cylindrical geometries can be found in appendix A of the supplementary material Supplemental_GONZALEZ_et_al_AIAA.pdf.

\section{The NPCC test rig experimental setup}

One important issue in combustion instability studies is that of the possible coupling between the injection system and the combustion chamber. In liquid rocket engines this coupling essentially involves the propellant manifold and injectors. In a typical liquid rocket engine, propellants are conveyed to the injectors through domes. The liquid oxygen dome directly feeds the central channels of the coaxial injectors while the annular channels are fed by the hydrogen dome. These domes are linked to the chamber through an injection plate often comprising several hundreds injectors forming a system which looks somewhat like a shower head. The large number of injectors allows, from an acoustic point of view, good communication between the domes and the thrust chamber. It is then quite possible that this may lead to a coupling, or interaction, between injection and combustion.

\section{A. The NPCC test configuration}

A New Pressurized Coupled Cavities test rig (or NPCC) has been developed in order to investigate acoustic interactions in coupled cavities as well as injector impedance and damping rates.

\section{Overall description}

The NPCC test rig is presented in figure 1. It consists in a series of rectangular cavities made of aluminum and 
(a)
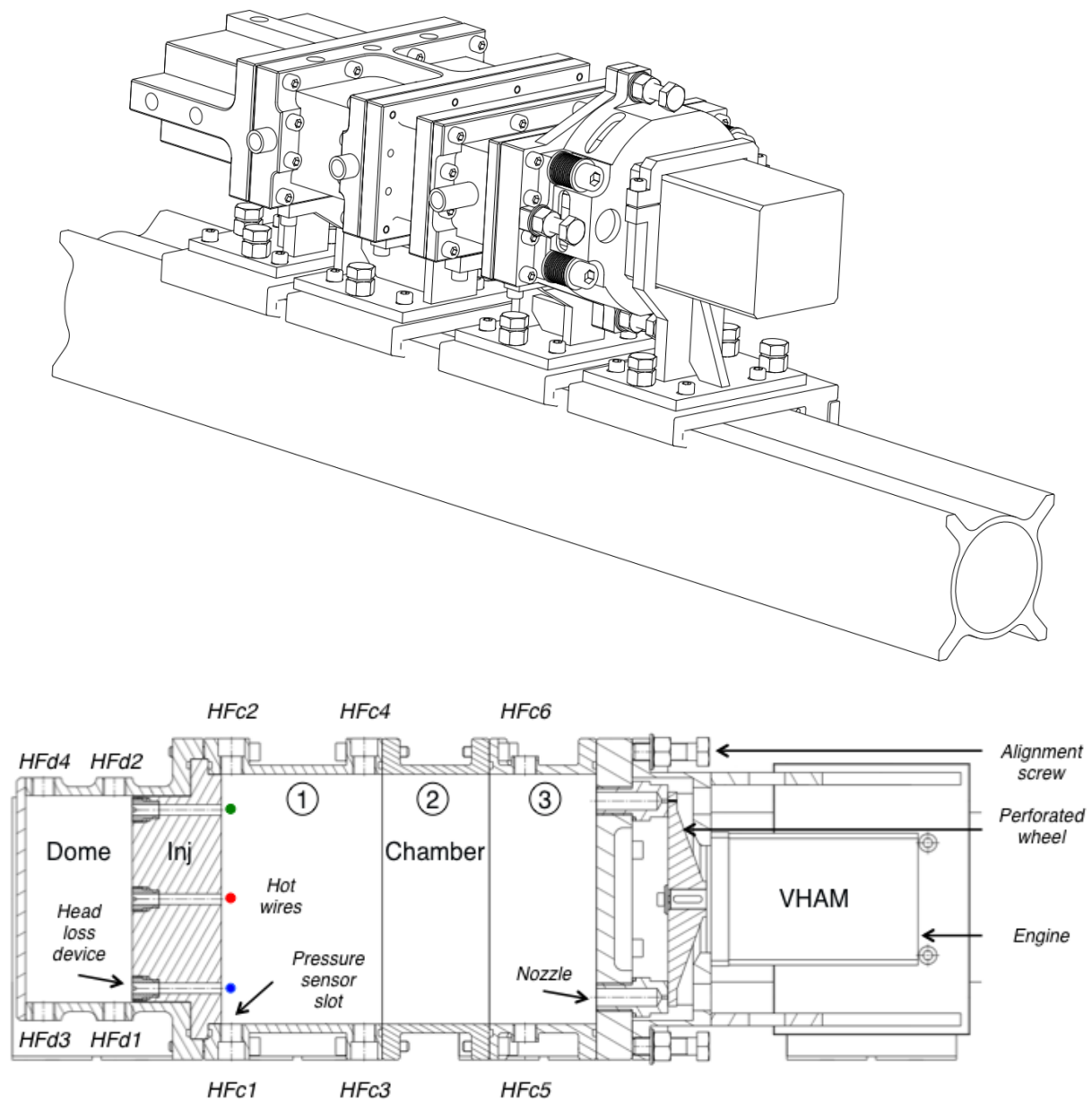

(b)

Fig. 1 (a) Overall view of the entire NPCC test rig. (b) Transverse cut of the rig featuring dome, injectors, chamber and VHAM (Very High Amplitude Modulator). The chamber is divided into three sectors: (1) Fixed upstream chamber block with pressure ports, (2) Interchangeable chamber block, (3) Fixed downstream chamber block with two pressure ports. Anemometric hot wires (from top to bottom HW1, HW2 and HW3) are located in the near vicinity of the injector exhaust sections.

stainless steel, mounted on a rail. In figure 1(b), from left to right, the first cavity is the dome fed by compressed air at ambient temperature. The dome is followed by a plate containing three channels, or injectors, of 6 mm in diameter. The injectors can receive diaphragms of different sizes to introduce various head losses. The $\xi$ coefficient defines the head loss:

$$
\xi=\frac{\Delta P}{\frac{1}{2} \rho \bar{u}^{2}}
$$

where $\Delta P$ is the total pressure difference between the dome and the chamber, $\rho$ is the density of the fluid flowing in the channel and $\bar{u}$ is the bulk inlet velocity. The head losses obtained experimentally with the different diaphragms are listed in table 1 
Table 1 Head loss coefficients corresponding to the different diaphragm diameters.

\begin{tabular}{ccc}
\hline Diameter of the diaphragm $[\mathrm{mm}]$ & $\Delta P / \bar{p}[\%]$ & Head loss coefficient $\xi[-]$ \\
\hline 6 & 0.04 & 4 \\
3 & 0.3 & 30 \\
2 & 4.8 & 400 \\
\hline
\end{tabular}

The next cavity is a modular (non reactive) chamber in three parts. Parts 1 and 3 are fixed while part 2 is interchangeable and of different lengths allowing changes in the length of the chamber. At the end of the chamber there is another plate containing two nozzles. These nozzles can be completely or partially obturated by a perforated wheel (see figure 1 in appendix B of the supplementary material Supplemental_GONZALEZ_et_al_AIAA.pdf for pictures of the VHAM and perforeted wheels) driven by a variable speed electric motor following the principles described in [18] and called Very High Amplitude Modulator (VHAM). The electric motor (Kollmorgen DBL3H00065-0R2-00K-S40) is characterized by a maximum rotation speed of $6000 \mathrm{rpm}$. The engine is controlled with a dedicated program, which defines a slow increase in rotation speed associated with a linear frequency ramp or it can run at a constant frequency in a continuous wave mode of operation. With the $N=69$ perforations of the standard wheel the maximum modulation frequency is $6900 \mathrm{~Hz}$. The perforated wheel and variable speed motor allows very high amplitude modulation as demonstrated in [18]. All elements of the test rig are mounted on a rail for a proper alignment.

\section{Instrumentation}

The NPCC test rig has been implemented with several ports for pressure measurements. Four are located in the dome and six in the chamber. Positions are chosen in order to clearly identify acoustic modes generated by the VHAM. Pressure sensors are 701A Kistler high frequency piezoelectric transducers. They are connected to a 5018 Kistler charge amplifier and linked to a computerized high frequency data logger.

Hot wire sensors are used to measure the instantaneous injection velocities. They are positioned at the injector outlets. The hot wire sensors, before use, are calibrated at the operating pressure. The operating pressure is $3.5 \mathrm{bar}$. The air stream is controlled by a mass flow meter. The hot wire signals are also acquired by the data logger. Hot wire measurements rely on King's law, which establishes a direct relation between the flow velocity and the voltage delivered by the sensor. King's law may be written as follows:

$$
V^{2}=A+B u^{1 / 2}
$$

where $V$ is the voltage, $u$ is the velocity component normal to the wire, $A$ and $B$ are the calibration constants. The calibration is carried out for several axial injection velocities. 


\section{The NPCC functioning}

The compressed air in the dome, or plenum, flows through the injectors feeding the chamber where the internal pressure is modulated by the VHAM. This modulation is carried out by obturating alternatively the nozzles so as to maintain a constant escaping flow rate and consequently a constant overall pressure in the chamber. This modulation creates, inside the cavities, acoustic waves that give rise to a series of standing modes. Each mode is characterized by its frequency and the positions of pressure nodes and anti-nodes. The inner dimensions of the dome and chamber were chosen so that the first transverse eigenmode of the dome $\left(1 \mathrm{~T}^{d}\right)$ corresponds to the first transverse first longitudinal eigenmode of the chamber $\left(1 \mathrm{~T} 1 \mathrm{~L}^{c}\right)$. The 1T1L mode in the chamber is a coupled mode, the other modes of the chamber being not coupled to the dome.

\section{B. Eigenmodes and eigenfrequencies}

The methodology to determine eigenmodes and eigenfrequencies in the NPCC test rig is detailed in appendix C of the supplementary material Supplemental_GONZALEZ_et_al_AIAA.pdf. A summary of all the eigenmodes found in this experiment is displayed in table 2 . The values deduced from the Helmholtz solver computations are quite close to those obtained with the ramp mode of operation.

Table 2 Eigenfrequencies obtained from AVSP and deduced from experiments on the NPCC configuration.

\begin{tabular}{lcccc}
\hline Eigenmode & 1T & 1T1L & 1T2L & 1T3L \\
\hline Calculated frequency $[\mathrm{Hz}]$ & 1210 & 1450 & 2009 & 2686 \\
NPCC measured frequency $[\mathrm{Hz}]$ & 1227 & 1465 & 2002 & 2789 \\
\hline
\end{tabular}

\section{Acoustic damping in coupled cavities}

It is difficult to identify all the mechanisms leading to damping. Damping may be caused by a number of phenomena. In a rocket engine these are thermal, viscous, turbulent dissipation mechanisms and energy transport driven out of the geometric domain across the nozzle. Admittance has been extensively studied theoretically and experimentally ([27-31]) and it is still today the subject of ongoing investigations. Thermal dissipation is the process by which a part of acoustic energy is converted into thermal energy. Thermal dissipation has been studied in many fields. One of the first papers dealing with thermal dissipation in acoustic cavities was that of [32]. The experimental investigation by [33] addressed different aspects of internal dissipation separately including thermal dissipation. More recently, the paper by [34] provides a comprehensive review of the theory including acoustic absorbers. Viscous dissipation is the component of the damping of acoustic oscillations due to resistance in the flow; [35] and [36] established the basis for acoustic motions due to the viscosity of the medium. This mode of dissipation has been extensively studied ([37- 39$])$. The work of [34] provides a good fundamental description of viscous dissipation in boundary layers and provides the basis of its application to acoustic resonators. Jet and turbulent dissipation is the dissipation of the acoustic energy contributing 
to the damping by the formation of vortices, which dissipate energy through transport out of the domain or through viscous dissipation. In the work of [34] resonator theory is used and the jet dissipation is addressed by the application of a resistant boundary layer at the resonator exit. Overall, damping is a complex process, which is difficult to predict and analyze, on a scale of a combustion chamber. It is generally considered that the determination of the damping rate requires experimental testing $([39,40])$. This is the approach that has been adopted in this work.

The damping coefficient determination is presented in appendix D of the supplementary material Supplemental_GONZALEZ_et_al_AIAA.pdf.

\section{A. Results and analysis for the nominal configuration}

The first case studied corresponds to the nominal configuration of the NPCC test rig that is: no diaphragms installed in the injector plate, the head loss coefficient $\xi$ is equal to 4 . The semi-perforated wheel is used with the VHAM and the modulation is set to cover the frequencies of $1 \mathrm{~T}, 1 \mathrm{~T} 1 \mathrm{~L}, 1 \mathrm{~T} 2 \mathrm{~L}$ and 1T3L modes. The operating absolute pressure is 3.5 bar and the total mass flow is $3.1 \mathrm{~g} . \mathrm{s}^{-1}$. In a standing wave field, the pressure sensors have to be positioned in pressure anti-nodes, where the amplitude of oscillation is maximum. The 1T, 1T1L, 1T2L and 1T3L modes that can be generated by the VHAM feature a pressure anti-node at the positions $\mathrm{HFc} 1$ and $\mathrm{HFc} 2$ (see figure 3 of appendix $\mathrm{C}$ of the supplementary material Supplemental_GONZALEZ_et_al_AIAA.pdf). Therefore, the recording of the pressure signal is presented at location $\mathrm{HFc} 1$ for all experimental cases. The recording is carried out during one minute at a sampling frequency of $50 \mathrm{kHz}$. Signals recorded at the position $\mathrm{HFc} 1$ are displayed in figure 2 The roughness in the signal waveform is attenuated by applying a low pass filter to the different waveforms with a cut-off frequency chosen above the modulation frequency and below the value of the next eigenfrequency. All pressure signals at HFc1 show periodic wave trains. In each of the pressure bursts, the signal first grows, reaches a maximum and decays to a minimum value. During the decay phase, the oscillations induced in the system are naturally damped and the acoustic level drops. The values of the damping rates are obtained by calculating the slope of the envelopes. For each mode, damping rates are determined for several decreasing slopes. The average values of damping rates obtained for the nominal configuration as well as the standard deviation of the damping rates are displayed in table 3 . It can be seen that

Table 3 Damping rates of four modes with their standard deviation for the nominal configuration $(\xi=4) . N$ is the number of slopes used for the determination of the damping rates and $\sigma$ is the relative standard deviation in percentage.

\begin{tabular}{lcccc}
\hline Mode & $1 \mathrm{~T}$ & 1T1L & 1T2L & 1T3L \\
\hline Damping rate $\left[\mathrm{s}^{-1}\right]$ & 36 & 85 & 61 & 101 \\
$N-\sigma[\%]$ & $30-4$ & $30-3$ & $30-4$ & $30-4$ \\
\hline
\end{tabular}

the method exhibits good repeatability since the relative standard deviations are equal to $4 \%$ or less. The damping rate of the 1T mode is the lowest of all the modes investigated. This is not surprising since the only dissipation mechanisms 
$1 \mathrm{~T}$

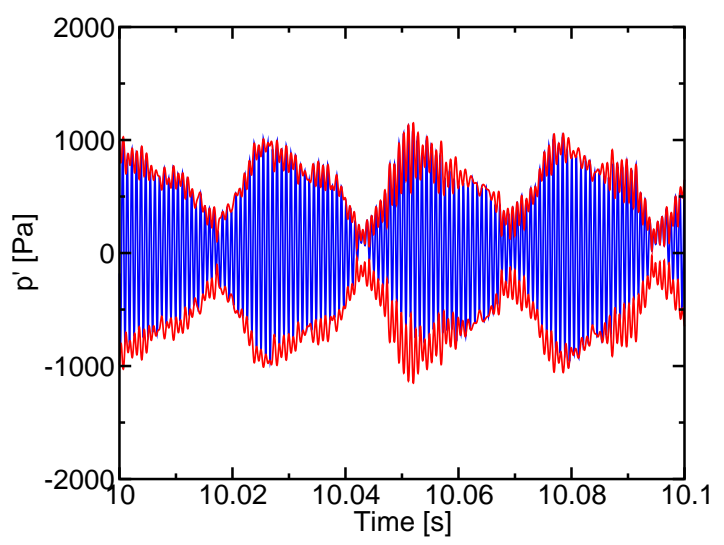

$1 \mathrm{~T} 2 \mathrm{~L}$

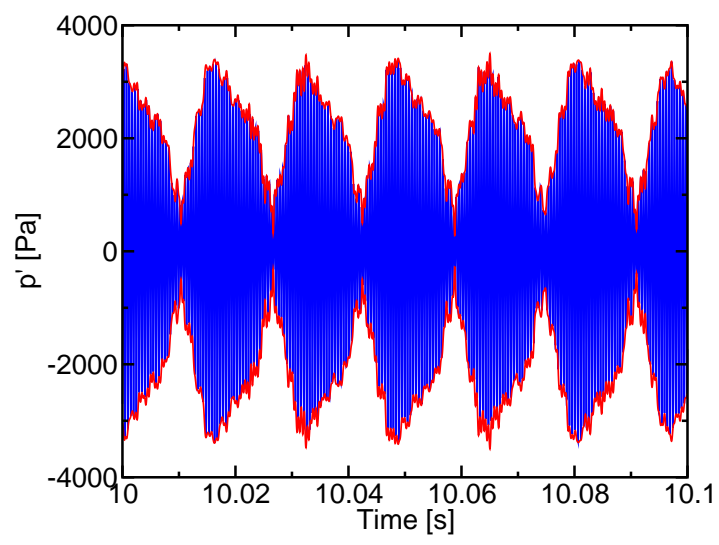

1T1L

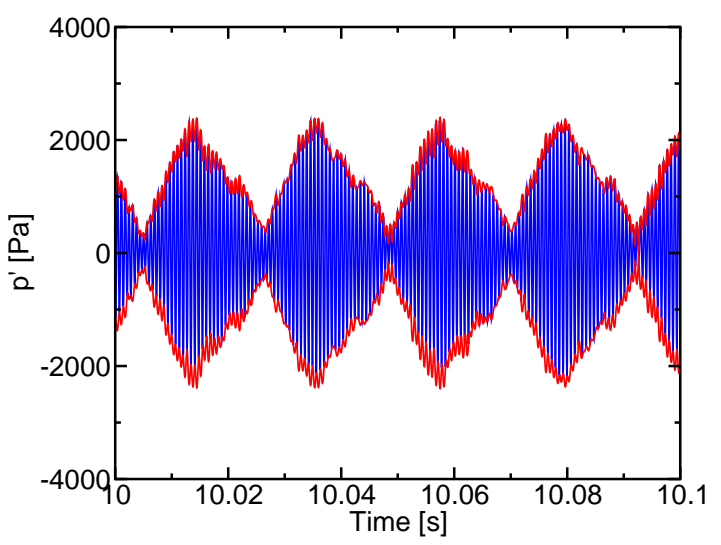

$1 \mathrm{~T} 3 \mathrm{~L}$

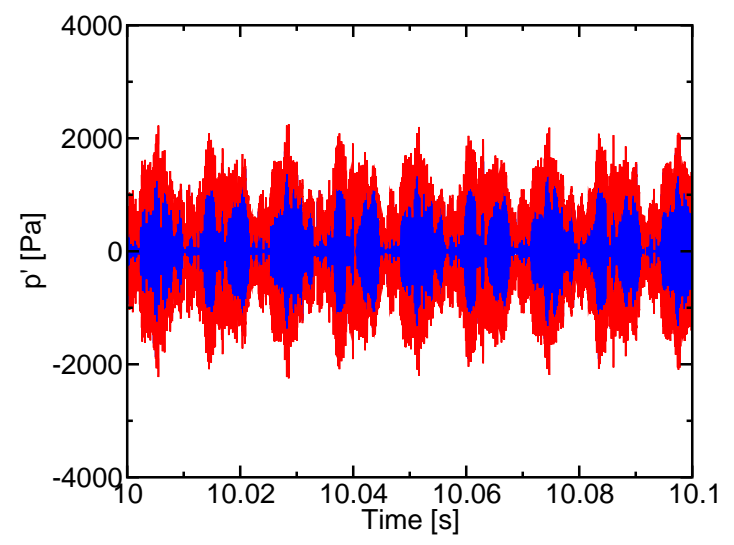

Fig. 2 Filtered pressure signal at HFc1 for four different at $\xi=4$. - (blue line) Pressure signal at HFc1, - (red line) envelope of the pressure signal at HFc1.

for this mode are thermal and viscous dissipation at the boundary layer. The other three modes have a longitudinal component in the direction of the nozzles that contributes to the dissipation of energy. The stronger the longitudinal component the higher the damping rates. Note that the 1T1L mode, which is the only one coupled with an eigenmode of the dome, exhibits a very high damping rate value compared to the other ones.

\section{B. Influence of head losses}

The head loss in the injector channels is changed by inserting diaphragms of different sizes. The three-millimeter in diameter diaphragm corresponds to a head loss coefficient $\xi=30$. Table 4 shows the values for the damping rates determined in this configuration.

Table 5 shows the values for the damping rates determined the two-millimeter in diameter diaphragms, corresponding to a head loss coefficient of $\xi=400$.

In figure 3 are plotted the damping rates versus the head loss coefficient. Figure 3 shows that in general the damping 
Table 4 Damping rates of four modes with their standard deviation for the NPCC test rig with 3 mm diaphragms $(\xi=30)$. $N$ is the number of slopes used for the determination of the damping rates and $\sigma$ is the relative standard deviation in percentage.

\begin{tabular}{lcccc}
\hline Mode & $1 \mathrm{~T}$ & $1 \mathrm{~T} 1 \mathrm{~L}$ & $1 \mathrm{~T} 2 \mathrm{~L}$ & $1 \mathrm{~T} 3 \mathrm{~L}$ \\
\hline Damping rate $\left[\mathrm{s}^{-1}\right]$ & 39 & 77 & 65 & 143 \\
$N-\sigma[\%]$ & $30-6$ & $30-4$ & $30-5$ & $30-4$ \\
\hline
\end{tabular}

Table 5 Damping rates of four modes with their standard deviation for the NPCC test rig with 2 mm diaphragms $(\xi=400) . N$ is the number of slopes used for the determination of the damping rates and $\sigma$ is the relative standard deviation in percentage.

\begin{tabular}{lcccc}
\hline Mode & $1 \mathrm{~T}$ & $1 \mathrm{~T} 1 \mathrm{~L}$ & $1 \mathrm{~T} 2 \mathrm{~L}$ & $1 \mathrm{~T} 3 \mathrm{~L}$ \\
\hline Damping rate $\left[\mathrm{s}^{-1}\right]$ & 42 & 72 & 83 & 187 \\
$N-\sigma[\%]$ & $30-5$ & $30-3$ & $30-5$ & $30-2$ \\
\hline
\end{tabular}

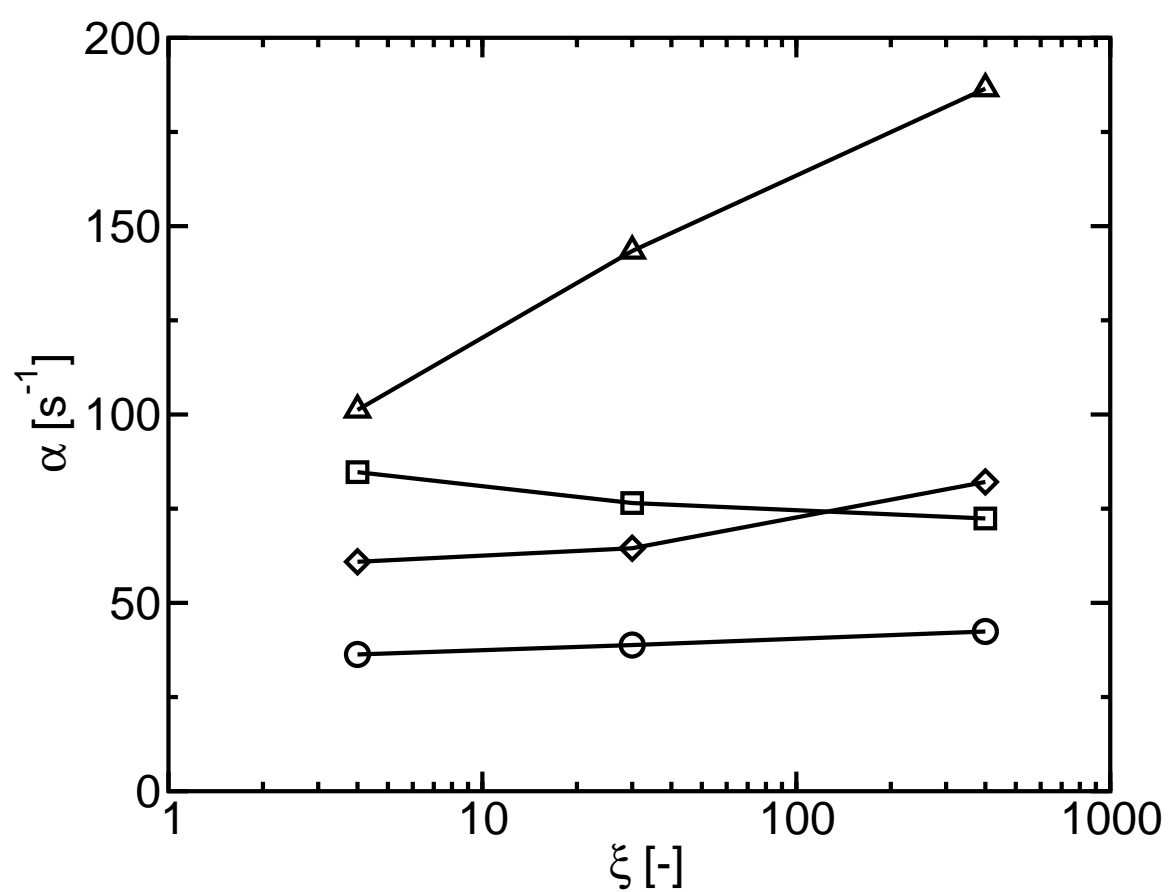

Fig. 3 Evolution of the damping rate with the head loss coefficient for $\bigcirc$ 1T, $\square$ 1T1L, $\diamond$ 1T2L and $\triangle 1$ T3L obtained with the relaxation method.

rate increases with the head loss coefficient. In fact, when the cross section of the injector decreases, gas velocity and turbulence increase leading to a rise of the turbulent dissipation component $([37,44])$. This is particularly true for the 1T2L and 1T3L eigenmodes. The damping rate of the first transverse mode, 1T, does not vary with the head loss coefficient. The 1T1L mode, which is the coupled mode of this configuration, does not follow the general trend. The damping rate of the 1T1L mode decreases with the head loss coefficient. This could be explained by the fact that when the head loss coefficient increases, the cavities (dome and chamber), tend to be decoupled from an acoustic point of view 
([42, 43]). This means that the volume in which the dissipation can occur becomes smaller, reducing the dissipation possibilities. On the other hand, in the absence of strong acoustic coupling between cavities, it is observed that the higher the frequency the stronger the damping. This is particularly the case for the viscous dissipation component of the damping rate ([34]).

\section{Development of a reduce order tool}

The possible occurrence of high frequency combustion instabilities in engines needs to be carefully investigated and usually requires systematic testing. The high frequency certification of rocket engines (see [44]) relies on a large number of tests that ensure that there are no accessible regions in the domain of operation where combustion instabilities might occur. The engine is usually tested on a bench in a wide range of conditions. Engine tests are quite expensive and some of them are believed to be superfluous. Ideally only a handful of operating conditions should be experimentally validated while the rest might be analyzed by simulation. These simulations need to provide a trend that indicates which parameters could trigger and drive combustion instabilities. It is believed that these simulations could be performed by using reduced order dynamical modeling. Ultimately, a reduced order dynamical code might be able to provide the required information. As the tool essentially can rely on integration in the time domain of a set of coupled differential equations one can imagine to scan many operating conditions.

\section{A. Global framework validation on the NPCC test rig}

Before using a reduced order tool on a full-scale rocket configuration, it is necessary to check the method (section (II) at laboratory scale. To do so, the equations of reduced order modeling are used to examine model scale cold flow geometry with the NPCC test rig. The experimental database of the pressure fluctuation in the cavities is used for direct comparison with calculations. As the NPCC test rig is a cold flow experiment, the simulation of its physical behavior requires a small number of models.

\section{Simulation preparation}

The first step of the simulation consists in choosing the appropriate framework. The geometry is that of the NPCC test rig equipped with the VHAM. The acoustic field is projected onto four eigenmodes: 1T, 1T1L, 1T2L and 1T3L determined in section III] The initial pressure field inside the NPCC test rig corresponds to no pressure fluctuation $p^{\prime}(\mathbf{x}, 0)=0$. There are no driving terms linked to combustion since it is a cold flow case configuration ( $S_{c o m b}$ in equation 201. The VHAM is an excitation source term $\left(S_{e x c}\right.$ in equation 20), it may be represented by a combination of two isolated acoustic sources operating in phase opposition. These sources appear as fluctuating mass flow rates in the 
mass balance equation (equation 23 .

$$
\frac{\partial \rho}{\partial t}+\nabla \cdot \rho \mathbf{u}=\dot{m}_{1} \delta\left(\boldsymbol{x}-\boldsymbol{x}_{1}\right)+\dot{m}_{2} \delta\left(\boldsymbol{x}-\boldsymbol{x}_{2}\right)
$$

Where $\boldsymbol{x}_{1}$ and $\boldsymbol{x}_{2}$ represent the nozzle positions. By using the modal expansion appearing in equation 1 , equation 23 yields a differential equation system for the modal amplitudes exhibiting the source term due to the action of the VHAM. Once identified this term can be cast in the form :

$$
\left.S_{e x c}^{m}(t)=\frac{1}{\Lambda_{m}}\left(\frac{d \dot{m}_{1}}{d t} \Psi_{m}\left(\mathbf{x}_{\mathbf{1}}\right) c^{2}+\frac{d \dot{m}_{2}}{d t} \Psi_{m}\left(\mathbf{x}_{\mathbf{2}}\right) c^{2}\right)\right)
$$

The total mass flow rate is modulated by the VHAM and $\dot{m}_{1}+\dot{m}_{2}=\dot{m}_{t o t}$. The modulated mass flow rates are then given by:

$$
\begin{aligned}
& \dot{m}_{1}=\frac{\dot{m}_{t o t}}{2}\left(1+\cos \left(\omega_{e} t\right)\right) \\
& \dot{m}_{2}=\frac{\dot{m}_{t o t}}{2}\left(1-\cos \left(\omega_{e} t\right)\right)
\end{aligned}
$$

where $\omega_{e}$ is the modulation angular frequency. Finally the excitation source term from the VHAM is expressed as:

$$
S_{e x c}^{m}(t)=\frac{\dot{m}_{t o t}}{2 \Lambda_{m}} \omega_{e} c^{2}\left(\Psi_{m}\left(\boldsymbol{x}_{1}\right)-\Psi_{m}\left(\boldsymbol{x}_{2}\right)\right) \sin \left(\omega_{e} t\right)
$$

The mass flow rate chosen is that specified in section [II] and the modulation frequencies correspond to the 1T, 1T1L, 1T2L and 1T3L determined with AVSP. The choice of the damping coefficient for each eigenmode is based on the values found in section IV (table 3). Under these conditions, the experimental data from sections [II and IV provide a basis for comparison with results obtained from the simulation.

\section{Results}

The pressure sensor positions mentioned in figure 1 (b) can be used to compare the temporal evolution of pressure fluctuations in the domain during the simulation. A pressure sensor at the HFc1 position is used to compare simulation results to the experimental data. Results are presented for four eigenmodes in figure 4 In equation 23, $100 \%$ of the total flow is modulated. Due to inevitable leaks between the nozzles and the perforated wheel in the experimental test rig, a fitting factor was added to take these leaks into account in the simulations. This fitting factor was determined from the 1T graph in figure 4 in regard to relative pressure amplitudes and was found to be equal to 0.8 . This means that $20 \%$ of the mass flow rate exiting the nozzles may not be modulated by the VHAM. It can be seen that for all studied cases the experimental curves and the simulation curves are in good agreement. The small phase shift between the experimental and simulated data is due to the difference in the frequencies found for the eigenmodes (table 2 ) and the experimental 
$1 \mathrm{~T}$ mode, $1210 \mathrm{~Hz}$

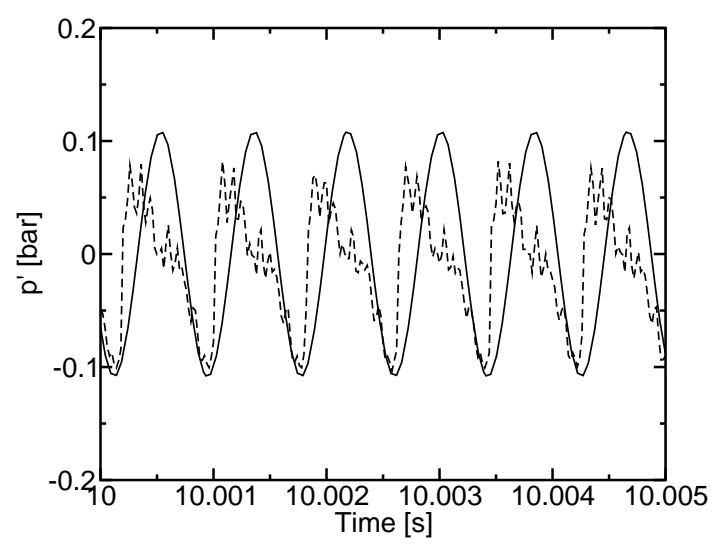

1T2L mode, $2009 \mathrm{~Hz}$

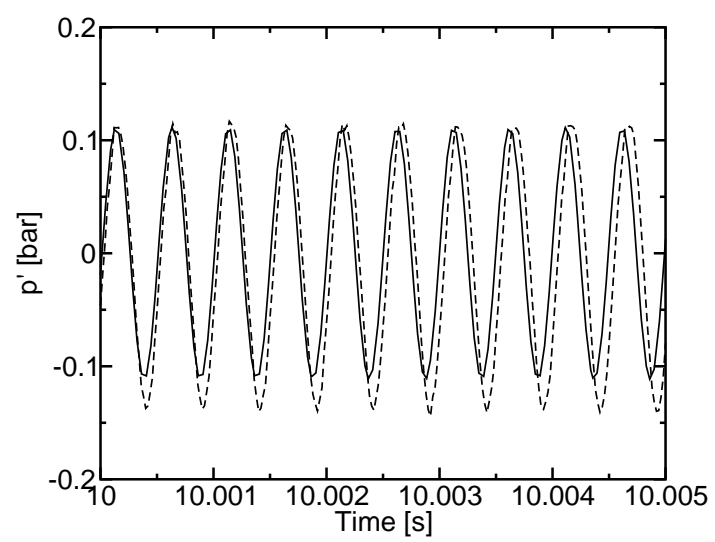

1T1L mode, $1450 \mathrm{~Hz}$

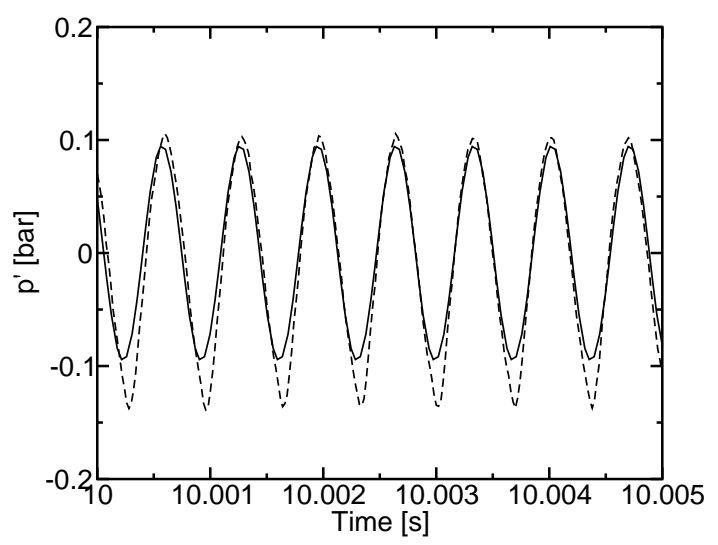

1T3L mode, $2686 \mathrm{~Hz}$

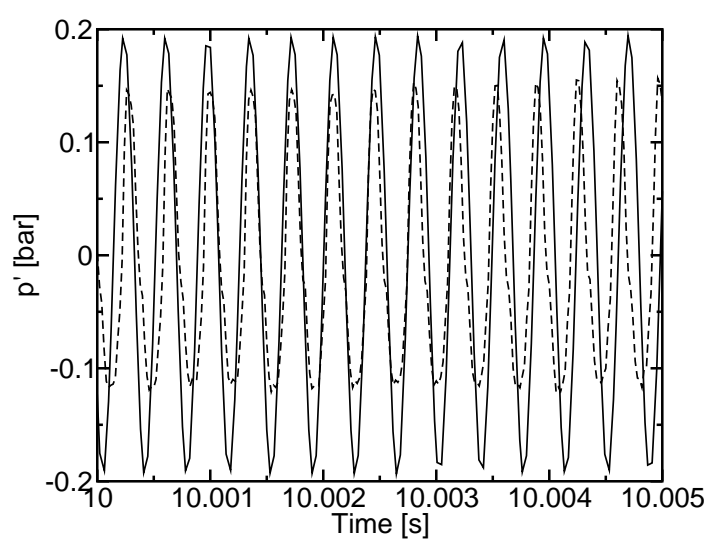

Fig. 4 Comparison between pressure signals from -- (dashed line) the experimental data and -(solid line) the simulation for four eigenmodes.

eignefrequencies. Only small differences in pressure amplitude between experimental and simulated data have been observed expect for the 1T3L mode that exhibits differences up to $30 \%$. This could be due to the difficulties in the treatment of the pressure signal (figure 2).

The reduced order modeling code was used to simulate the NPCC configuration and determine the pressure fluctuations in the cavities. The inputs for the code were the geometry of the test rig, the thermodynamic conditions under which the rig operates, the definition of an exterior source term (the VHAM in this case) and the damping rates determined in section $[\mathrm{IV}]$ The pressure signals from the reduced order simulation and the experimentation at position $\mathrm{HFc} 1$ are in good agreement. This indicates that the reduced order code performs well under our testing conditions, provided the correct source term models and damping rates are chosen. 


\section{B. Modeling at full scale}

Reduced order modeling consists in replacing complex coupled processes with simpler descriptions. These simplified models are treated independently and linked together in the final stage. The objective is to derive a state space description of the coupled dynamics of the system under investigation. This description involves a system of differential equations in combination with a set of algebraic relations. Stability calculations are then carried out in the time domain. The aim of reduced order dynamical modeling of combustion instabilities is to represent, in an idealized fashion, the processes which govern the system dynamics. The code presented here can be used to test dynamical models and validate novel formulations of the processes driving instabilities. The code relies on a physical expansion of state variables in terms of the system eigenmodes (equation 11. There are many possible expressions for the different terms appearing in equation 1. Specific formulations can be chosen at the start of the simulation to represent a particular condition. The various options are defined by the user, the code then integrates the set of equations (equation 19] providing the space-time distribution of unsteady pressure in the system. To run a dynamical simulation one has to follow the steps indicated in figure 5. The user first defines a system to be simulated. Typically, the systems studied in combustion instabilities

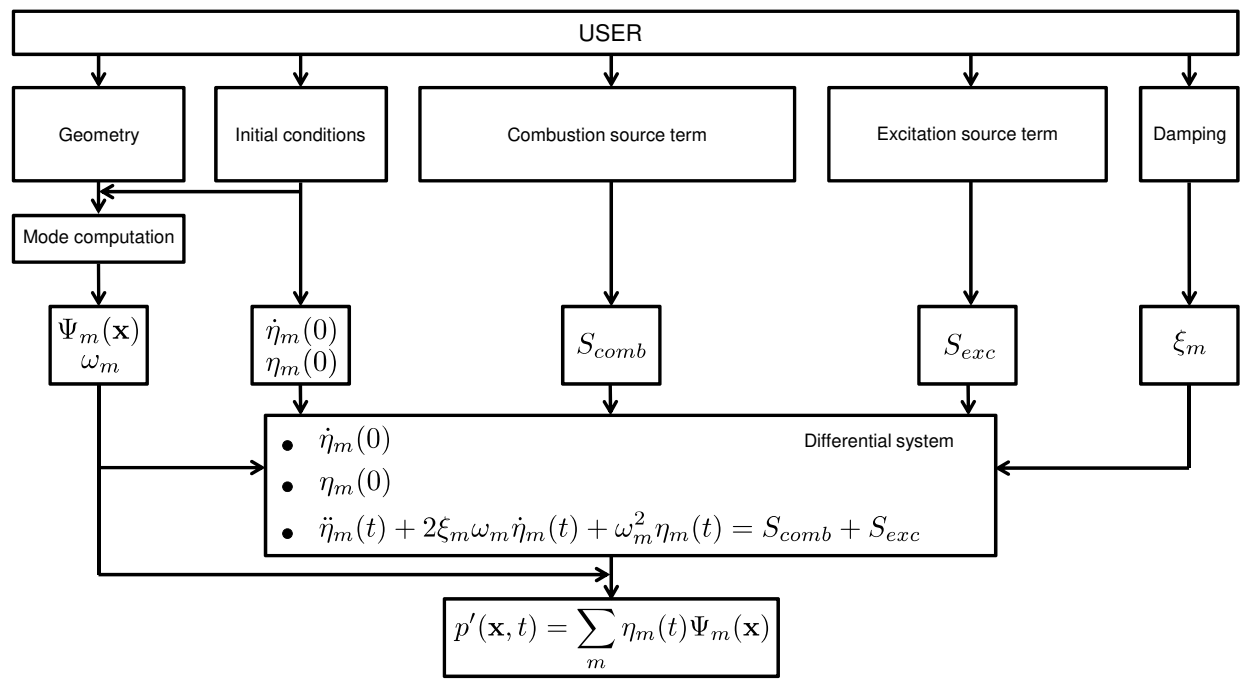

Fig. 5 Global framework of the reduced order tool based on modal projection.

are comprised of cavities linked by injectors. The system is meshed in order to compute the pressure variations on each cell and acoustic boundary conditions are defined in order to describe the pressure and velocity behaviors at the system limits. The initial conditions (pressure and sound velocity) are set by the user to determine on the one hand the eigenmodes and eigenfrequencies and on the other hand to set the variables of the simulation. This operation allows the 
determination of: $\left(\Psi_{m}(\mathbf{x}), \omega_{m}\right)$ and $\left(\dot{\eta}_{m}(0), \eta_{m}(0)\right)$ respectively. Before the simulation is carried out, the user must analyze the operating points he wishes to compute and determine which driving mechanisms will be dominant in the desired configuration. These driving mechanisms linked to the combustion process or exterior excitation terms defined as $S_{c o m b}$ and $S_{\text {exc }}$ respectively. Finally the damping coefficient associated to each eigenmode $\left(\xi_{m}\right)$ is included into the code. The code resolves the differential equations defined by equation 20 and determines the pressure amplitudes $\eta_{m}$ which are then combined with the eigenmodes to form the field of pressure inside the system, $p^{\prime}(\mathbf{x}, t)$.

\section{Initial conditions}

To start the simulation it is necessary to provide initial distributions of the state variables. This may be done by defining a field at rest with no pressure fluctuations and sound velocities corresponding to the thermodynamic state in which fluids are. More complex initial fields may be extracted from LES computations and superimposed onto the mesh of the system. One may also define an initial energy release rate distribution corresponding to a deposition of energy over a finite region $([45])$.

\section{Modal identification}

For a typical geometry like that of a rocket engine one has to prepare a mesh describing the system cavities (injection plenum, thrust chamber, injector channels). This is then used to determine the eigenfrequencies and eigenfunctions using a Helmholtz solver. The code uses AVSP ([46, 47]) to determine the modal structures and eigenfrequencies. The user then chooses the relevant number of eigenmodes on which the modal projection will be carried out.

\section{Combustion source term}

There are many possible mechanisms that may drive instabilities in the combustion process.

Fluctuations of the jet are induced by transverse velocity fluctuations. The dense core jet is transported by the acoustic motion, this assumption is at the heart of the Flame Acoustic Motion Equation (FAME), first developed by [18]. The name of this model implies that the unsteady heat release is caused by the flame motion itself. The following development is for Cartesian geometries. The flame is assumed to be a thin sheet, the fluctuations of the heat release, $\dot{Q}^{\prime}$, caused by the transverse velocity fluctuations $v^{\prime}$ is defined by equation 28 (for more details see [18]).

$$
v^{\prime}(\boldsymbol{x}, t)=\frac{c^{2}}{\bar{p} \gamma} \sum_{m=1}^{\infty} \frac{1}{\omega_{m}^{2}} \dot{\eta}_{m}(t) \nabla \Psi_{m}(x)
$$

There are no transverse velocity fluctuations for a pressure mode corresponding to $m=0$ this is why the sum in equation 28 begins with $m=1$. The FAME model, which links $\dot{Q}^{\prime}$ with $v^{\prime}([18])$ can be applied. The flame of length $L_{f}$ is positioned at $y_{0}$ and oscillates up and down. This motion is induced by the acoustic velocities inside the domain. The steady heat release rate from an injector is noted $Q$. Assuming an infinitely thin flame the heat release is defined by 
equation 29.

$$
\dot{Q}(\boldsymbol{x}, t)=\frac{Q}{L_{f}} \delta(y-y(t)) \delta\left(z-z_{0}\right)
$$

where $z_{0}$ designates the initial position of the flame in the $z$ direction. Equation 29 indicates that the steady heat release rate $Q$ of the flame is generated over its entire length $L_{f}$ at its coordinates $\left(y(t), z_{0}\right)$. The combustion source term for this model can be written as (see [48] for details):

$$
S_{c o m b}^{m}(t)=4 \frac{\gamma-1}{\gamma} \frac{Q}{\bar{p} \Lambda_{1}} \dot{\eta}_{1}(t) \sum_{n=1}^{N_{f}} \frac{\tan \left(\frac{\pi y_{0}^{n}}{2 l}\right) e^{-\frac{2 \eta_{1}(t)}{\gamma \bar{p}}}}{\left(1+\tan ^{2}\left(\frac{\pi y_{0}^{n}}{2 l}\right) e^{-\frac{2 \eta_{1}(t)}{\bar{p} \gamma}}\right)^{2}}
$$

where $\Lambda_{1}=\iiint \cos ^{2}\left(\frac{\pi}{l} y\right) d x d y d z=L h l / 2$ represents the square of the norm of $\Psi_{1}, N_{f}$ is the total number of flames and $y_{0}^{n}$ is the initial position of the $n^{\text {th }}$ flame. This source term indicates that in configurations with multiple injectors such as rocket engines, the combined heat release fluctuations from the unit flames add up to produce a source term that could drive the instability.

In a cylindrical configuration, like those of combustion chambers, it is more appropriate to write the equations in a cylindrical coordinate system. The fluctuating velocity is given by:

$$
\mathbf{v}_{\mathbf{m}}^{\prime}(\boldsymbol{x}, t)=\dot{r}(\boldsymbol{x}, t) \mathbf{u}_{\mathbf{r}}+r(\boldsymbol{x}, t) \dot{\theta}(\boldsymbol{x}, t) \mathbf{u}_{\theta}
$$

where $r$ and $\theta$ are the radial and angular position of the flame. The flame is here considered to be anchored at the injector of coordinates $\left(r_{0} ; \theta_{0}\right)$ and move only in the azimuthal direction in a cylinder of radius $r_{0}$, as explained in [48]. Under these conditions, $\dot{r}$ is equal to zero. The steady heat release rate from an injector is noted $Q$. Assuming an infinitely thin flame the heat release is now defined by:

$$
\dot{Q}(\boldsymbol{x}, t)=\frac{Q}{L_{f}} \delta\left(r-r_{0}\right) \delta[\theta-\theta(t)]
$$

where $r_{0}$ is the initial radial position of the flame. The combustion source term for this model, when projected onto the two modal structures that define a spinning mode can be written as (see [48] for details):

$$
\begin{aligned}
& S_{c o m b, c}^{m}(t)=\frac{\gamma-1}{\gamma} \frac{1}{b_{m} c} \frac{Q}{\bar{p} V} \frac{1}{\left(\kappa_{m} R\right)^{2}} \dot{\eta}_{m}(t) \sum_{n=1}^{N_{f}} \frac{R^{2}}{r_{n}^{2}}\left[\frac{\partial \Psi_{m c}}{\partial \theta}\left(r_{n}, \theta_{n}\right)\right]^{2} \\
& S_{c o m b, s}^{m}(t)=\frac{\gamma-1}{\gamma} \frac{1}{b_{m} s} \frac{Q}{\bar{p} V} \frac{1}{\left(\kappa_{m} R\right)^{2}} \dot{\eta}_{m}(t) \sum_{n=1}^{N_{f}} \frac{R^{2}}{r_{n}^{2}}\left[\frac{\partial \Psi_{m s}}{\partial \theta}\left(r_{n}, \theta_{n}\right)\right]^{2}
\end{aligned}
$$


where $b_{m} i=\Lambda_{m} / \pi R^{2} L, \Lambda_{m i}=\int_{V} \Psi_{m i}^{2} r d r d \theta d x, V=\pi R^{2} L$ is the volume of the cylindrical domain, $\kappa_{m}=\omega_{m} / c$ is the wave number, $\left(r_{n}, \theta_{n}\right)$ are the cylindrical coordinates of the $\mathrm{n}^{\text {th }}$ flame and $N_{f}$ is the total number of flames. The subscripts $s$ and $c$ differentiate the perpendicular components of eignemodes of a cylindrical geometry. The combustion source terms defined in equations 30, 33 and 34 are weak in pressure anti-nodes but strong in pressure nodes.

Fluctuations in the heat release rate may be caused by pressure variations inside the combustion chamber as demonstrated in previous work $([11,18,48-50])$. The heat release per unit of surface is now considered to be proportional to the square root of the pressure ([49]), equation 35 .

$$
\dot{q}_{s}\left(\mathbf{i}_{\mathbf{i n j}}, t\right) \propto \sqrt{p}\left(\mathbf{i}_{\mathbf{i n j}}, t\right)
$$

where $\mathbf{i}_{\mathbf{i n j}}$ is the index for an injector. In the case of cryogenic combustion the chemistry can be considered to be infinitely fast. Let us now consider the $j^{\text {th }}$ injector and let $\dot{Q}_{T}$ be the total heat release rate corresponding to the flame anchored at this injector. It is convenient to assume that the heat release takes place at a point $\boldsymbol{x}_{E j}$ of this flame. The mean heat release rate per unit volume may then be described by $\overline{\dot{Q}}_{j}=\bar{Q}_{T} \delta\left(\boldsymbol{x}-\boldsymbol{x}_{E j}\right)$ and the fluctuation of this quantity may then be deduced by linearizing equation 35 into:

$$
\frac{\dot{Q}_{j}^{\prime}}{\overline{\dot{Q}}_{j}}=\frac{1}{2} \frac{p^{\prime}}{\bar{p}}
$$

The combustion source term for this model can be written as (see [48] for details):

$$
S_{c o m b}^{m}(t)=\frac{1}{2} \frac{\gamma-1}{b_{m}} \frac{\bar{Q}_{T}}{\bar{p} V} \dot{\eta}_{m}(t) \sum_{j=1}^{N_{f}} \Psi_{m}^{2}\left(\boldsymbol{x}_{E j}\right)
$$

where $b_{m}=\Lambda_{m} / V, \Lambda_{m}=\int_{V} \Psi_{m}^{2} d V, V$ is the volume of the domain and $N_{f}$ is the number of flames. It is worth mentioning that the combustion source term presented in equation 37 is weak in pressure nodes and strong in pressure anti-nodes.

\section{Excitation source term}

In addition to the combustion source terms, it is useful to implement an external actuator to allow calculations of modulated configurations such as the NPCC test rig. The model corresponding to the VHAM actuator has been described earlier in section V.A.1 with equation 27.

\section{Damping}

Dissipation of acoustic energy is represented by damping terms describing energy losses through the nozzle, the cavities and in the injector channels. Damping can be increased by connecting resonators or quarter wave cavities to the 
thrust chamber or by inserting baffles to subdivide the injection backplane. Under reactive conditions, further damping can be induced by temperature fluctuations ([51]), mass momentum, flow reconfiguration and heat transfer relaxation associated with the spray of droplets. Acoustic non-linearities may have a great impact on damping as well. It has been shown $([42])$ that non-linear terms define the limit cycle observed during high-frequency instabilities. In its present form the damping terms are constant parameters, which are typically included in the differential set of equations as first order time derivatives. If the source term becomes greater than damping, the system becomes unstable and the oscillation amplitude grows exponentially. In actual situations, the non-linear combustion response leads to a finite

amplitude limit cycle. A realistic estimation of the chamber acoustic damping is difficult to achieve in general. One may for example try to estimate the linear damping at the chamber walls following an analytical method described in [34].

\section{A case study: the BKD engine}

\section{A. Simulation preparation}

The full-scale rocket engine proposed for this study is the BKD test rig operated at DLR Lampoldshausen Germany. This engine is interesting because, under certain conditions it becomes naturally unstable. The BKD test rig is presented in appendix E of the supplementary material Supplemental_GONZALEZ_et_al_AIAA.pdf. This study will focus on two load points LP3, a stable operating point and LP4 an unstable load point.

\section{Initial conditions}

The initial field for the simulation corresponds to cold propellants in the dome and injectors and hot burnt gases in the thrust chamber. The combustion region is represented by a thin zone located at the injection plane. This generates a local gradient of sound velocity in the injector area. The initial solution provides the field of sound velocity inside the geometry (figure 6) to solve the Helmholtz equation.

\section{Modal identification}

The eigenmodes and eigenfrequencies of the BKD are obtained with the AVSP code. Before running this code it is necessary to impose the mean temperature distribution onto the mesh of the BKD test rig, figure 6 This mesh comprises 228000 nodes and 1105000 tetrahedra. Hydrogen dome and feeding lines are neglected, as they are expected to be weakly coupled with the chamber. The initial solution provides the initial conditions defining the mean density and temperature in the system. The thermodynamic conditions in the dome are those of a real gas. The data was taken from the NIST database $([52])$. In the injectors downstream side, the temperature and pressure are set to reflect the hot environment of the combustion chamber. The sound velocities in the chamber are those determined experimentally by DLR: 1,200 m.s for LP3 and 1,400 m.s ${ }^{-1}$ for LP4. The various walls are treated as rigid boundaries (zero normal velocity) except for the nozzle, which is represented by an admittance condition ([53]). A set of eigenfrequencies 


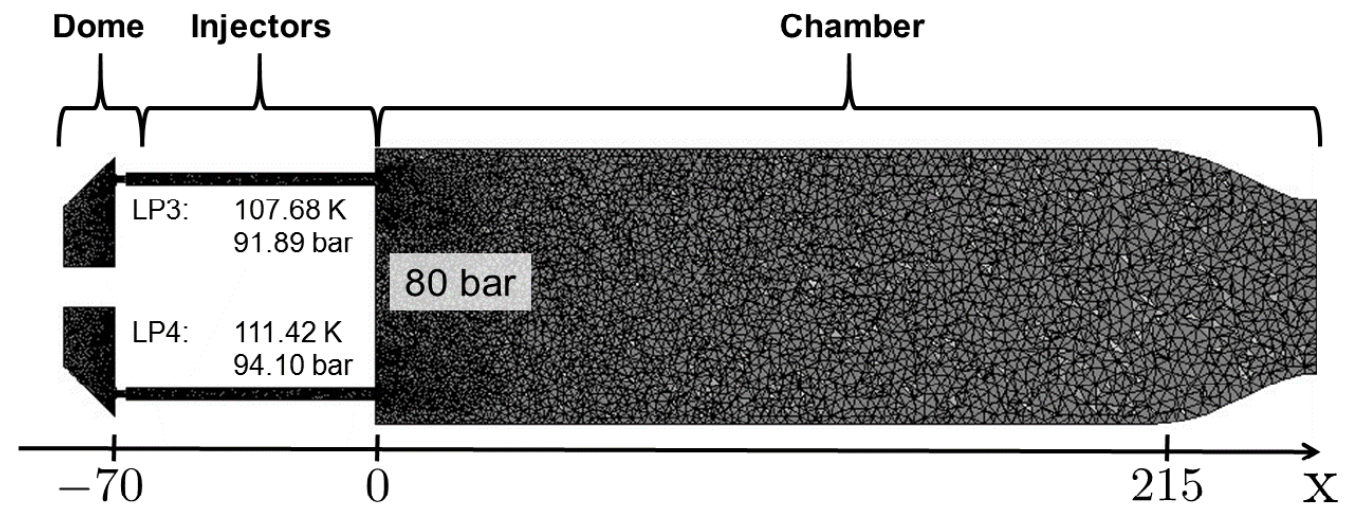

Fig. 6 Longitudinal slice of the mesh used in the modal identification carried out with AVSP and injection conditions corresponding to LP3 and LP4 operating points.

and modes for LP3 (the stable load point corresponding to injection of low temperature hydrogen) and modes for LP4 (the unstable load point corresponding to higher temperature hydrogen injection) can be found in appendix F of the supplementary material Supplemental_GONZALEZ_et_al_AIAA.pdf. Eigenfrequencies for cases LP3 and LP4 are shown in table 6. The most dangerous modes are the azimuthal ones and will be used as basis of projection.

Table 6 Eigenfrequencies for cases LP3 and LP4.

\begin{tabular}{lcccc}
\hline Mode & 3L & 1A & 1A1L & 1A2L \\
\hline Frequencies for case LP3 [Hz] & 6565 & 8167 & 8606 & 9482 \\
Frequencies for case LP4 [Hz] & 9991 & 10280 & 10749 & 11811 \\
\hline
\end{tabular}

Pure longitudinal modes, that occur at lower frequencies, are not taken into consideration since only high frequency oscillations are being investigated. Higher order azimuthal modes (like 2A and above) occur at frequencies that can be left out, at least in a first analysis. The basis of projection is then 1A, 1A1L and 1A2L for LP3 and LP4.

\section{Combustion source term}

The combustion source term $S_{\text {comb }}$ in equation 20 can be attributed to a wide range of phenomena. For LP3 and LP4, the average pressure in the chamber is $8 \mathrm{MPa}$. The total power of the BKD engine can be estimated around $87 \mathrm{MW}$ for both points. The BKD has 42 injectors which means that the average heat release rate per injector is around 2.07 MW. There are many possible mechanisms that may drive instabilities in rocket engines, among others, movement of the jet caused by transverse velocity variations that generate fluctuations of the heat release rate $([16,18,20,48,54,55])$ as well as pressure variations in front of the injectors $([11,18,48,-50])$. Therefore the combustion source terms chosen for the simulation of LP3 and LP4 are those defined by equations 33,34 and 37 


\section{Excitation source term}

In the case of the BKD engine, there are no external actuator for LP3 and LP4, therefore the excitation source term $S_{\text {exc }}$ is equal to zero.

\section{Damping}

It was indicated in section IV that the level of damping was not easy to determine with precision because the sources of damping are not well identified and there is no analytical method to evaluate the damping coefficient of a given configuration. There is no data available for damping coefficients of the BKD engine, however the use of the actual damping coefficients is required. To overcome this difficulty we have proceeded as follows: we have set damping coefficients that make LP4 just unstable and these values were kept constant for LP3. Table 7 provides the damping rate values used for LP3 and LP4.

Table 7 Values, for each eigenmodes, of the damping rates used for the reduced order modeling of the BKD.

\begin{tabular}{lccc}
\hline Mode & 1A & 1A1L & 1A2L \\
\hline Adjustment damping rate $\left[\mathrm{s}^{-1}\right]$ & 2258 & 2482 & 2592 \\
\hline
\end{tabular}

\section{B. Results and discussion}

During the reduced order simulations, the pressure signal was recorded at two positions corresponding to two of the pressure sensors of the BKD test rig. This signal is used to follow the evolution of the pressure field close to the thrust chamber backplane. The initial solution is, in this test, uniform over the whole domain (this corresponds to a spatially constant perturbation). This initial solution is projected on a basis comprising the first three azimuthal modes (1A, 1A1L and 1A2L). Other modes are also triggered but their influence will not be calculated here. This is acceptable if the modes are weakly coupled (i.e. each mode is essentially independent of the others). Figure 7 (a) displays the pressure signal for LP3. The oscillations generated by the uniform perturbation are damped so that the pressure oscillation amplitude decreases with time. The instability driving mechanisms are weaker than damping. This behavior is characteristic of a stable system.

The pressure signal corresponding to the simulation of LP4 is displayed in figure 7 b). In this case the amplitude of pressure fluctuations increases with time. The growth rate exceeds the damping rate and the system becomes unstable. A closer look at the temporal evolution of pressure fluctuations for LP4 (figure 7(b)) indicates that the pressure diverges fairly quickly. In general, the amplitude of pressure oscillations reaches a limit value. This limit cycle, due to non linearities has not been included on our simulations.

The previous simulations indicate that reduced order modeling is able to distinguish between stable and unstable conditions in this case after adjusting the damping coefficients of the different modes and using the combustion/acoustic coupling mechanisms. 


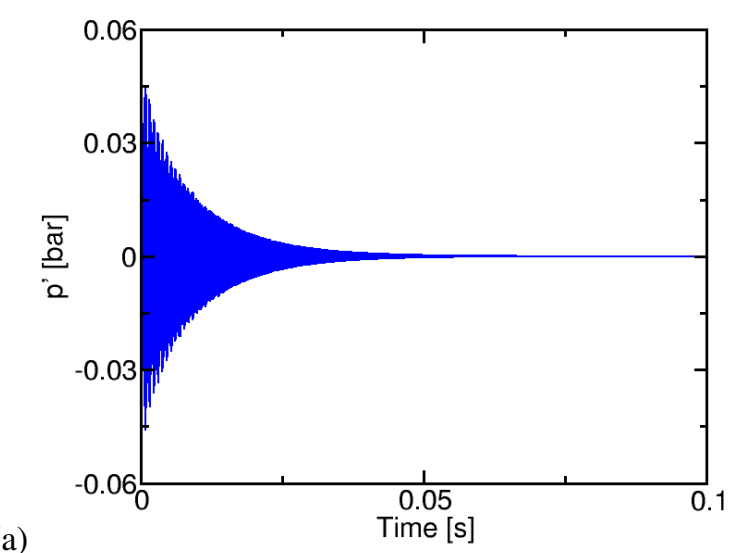

(a)

\section{Fig. 7 (a) Temporal evolution of the pressure fluctuation inside the BKD test rig for LP3. (b) Temporal evolution of the pressure fluctuation inside the BKD test rig for LP4.}

\section{Conclusions}

The reduced order modeling method presented in section III relies on a modal expansion of the pressure field. It has been shown that the amplitudes in the modal expansion are determined by a set of second order differential equations. These equations contain, in particular, the modal projection of the rate of change of the non steady heat release rate. This framework together with the driving and damping models can be used to analyze and eventually predict combustion instabilities with an engineering reduced order tool.

Issues associated with injector dynamics, coupling between dome and chamber and damping rate estimation were treated in section III] The test rig configuration developed in this work has various features including a modular design, an efficient interface between the exhaust nozzles and the rotating wheel of the VHAM, an easier access to the injector plate and the possibility to easily change injector head losses. The addition of pressure sensors in the two cavities allows the proper determination of the acoustic mode generated by the VHAM. This configuration was used to determine the global damping rate associated with each eigenmode, examine the system response, identify eigenmodes and eigenfrequencies and analyze effects induced by changes in injector head losses.

The experimental approach adopted in section [V] allowed the determination of the damping rates for four eigenmodes of the NPCC test rig. The increase of the damping rate with the head loss coefficient was consistent with previous knowledge. The particular behavior of the 1T1L mode damping rate observed has been explained in terms of decoupling between the dome and the chamber. The relaxation method has proved to be robust and exhibits good repeatability.

The BKD test rig, an experimental rocket engine operated at DLR Lampoldshausen Germany, was used to test the principles of reduced order modeling described in section III. The eigenmodes found with the Helmholtz solver AVSP reveal that there is a notable difference in the modes corresponding to the stable and unstable load points. The reduced order tool developed in this work was used to simulate two load points of the BKD with the introduction of two flame/acoustic coupling mechanisms from previous work. The absence of data for the damping of the BKD test rig 
required an adjustment of damping coefficients. The dataset of load point LP4 was used and LP3 was shown to be stable after the attribution of the same damping coefficient for both cases. The study of LP3 and LP4 is not a formal model validation. It can be seen, however, as an example of how this kind of tool can be used.

The reduced order dynamic modeling developed in this work, constitutes an attempt to represent complicated couplings between acoustic modes and combustion. Advantages are simplicity and effectiveness. Damping rates remain the major unknown in practical cases and should be the focus of further investigations.

\section{Acknowledgements}

Authors would like to acknowledge CNES and SAFRAN for their participation to the funding of this research.

\section{References}

[1] Crocco, L., "Aspects of combustion instability in liquid propellant rocket motors. Part I: Fundamentals. Low Frequency Instability With Monopropellants," J. Am. Rocket Soc., Vol. 21, 1951, pp. 163-178.

[2] Tsien, H. S., “Servo-stabilization of combustion in rocket motors," J. Am. Rocket Soc., Vol. 22, No. 5, 1952, pp. $256-262$.

[3] Oefelein, J. C., and Yang, V., “Comprehensive Review of Liquid-Propellant Combustion Instabilities in F-1 Engines,” Journal of Propulsion and Power, Vol. 9, No. 5, 1993, pp. 657-677.

[4] Oefelein, J. C., "Thermophysical characteristics of shear-coaxial LOx-H2 flames at supercritical pressure," Proceedings of the Combustion Institute, Vol. 30, No. 2, 2005, pp. 2929 - 2937. doi:10.1016/j.proci.2004.08.212, URL http://www. sciencedirect.com/science/article/pii/S0082078404002681.

[5] Hakim, L., Schmitt, T., Ducruix, S., and Candel, S., "Dynamics of a transcritical coaxial flame under high-frequency transverse acoustic forcing: the effect of a modulation frequency," Combustion and Flame, Vol. 162, 2015, pp. 3482-3502.

[6] Hakim, L., Ruiz, A., Schmitt, T., Boileau, M., Staffelbach, G., Ducruix, S., Cuenot, B., and Candel, S., "Large eddy simulations of multiple transcritical coaxial flames submitted to a high-frequency transverse acoustic modulation," Proceedings of the Combustion Institute, Vol. 35, No. 2, 2015, pp. 1461 - 1468. doi:http://dx.doi.org/10.1016/j.proci.2014.05.142, URL http://www.sciencedirect.com/science/article/pii/S154074891400145X

[7] Schmitt, T., Selle, L., Cuenot, B., and Poinsot, T., "Large-eddy simulation of transcritical flows," Compte Rendus-Mécanique, Vol. 337, No. 6-7, 2009, pp. 528-538.

[8] Masquelet, M., Menon, S., Jin, Y., and Friedrich, R., "Simulation of unsteady combustion in a LOX-GH2 fueled rocket engine," Aerospace Science and Technology, Vol. 13, No. 8, 2009, pp. 466-474.

[9] Candel, S., Durox, D., Schuller, T., Darabiha, N., Hakim, L., and Schmitt, T., "Advances in combustion and propulsion applications," European Journal of Mechanics - B/Fluids, Vol. 40, 2013, pp. 87 - 106. 
[10] Urbano, A., Selle, L., Staffelbach, G., Cuenot, B., Schmitt, T., Ducruix, S., and Candel, S., "Exploration of combustion instability triggering using Large Eddy Simulation of a multiple injector liquid rocket engine," Combustion and Flame, Vol. 169, 2016, pp. 129 - 140. doi:http://dx.doi.org/10.1016/j.combustflame.2016.03.020, URL http://wwW.sciencedirect. com/science/article/pii/S0010218016300372

[11] Urbano, A., Douasbin, Q., Selle, L., Staffelbach, G., Cuenot, B., Schmitt, T., Ducruix, S., and Candel, S., "Study of flame response to transverse acoustic modes from the LES of a 42-injector rocket engine," Proceedings of the Combustion Institute, 2016, pp. -. doi:http://dx.doi.org/10.1016/j.proci.2016.06.042, URL http://www . sciencedirect.com/science/ article/pii/S1540748916301006

[12] DLR, “TEST CASE HF-7 - LOx/H2 Combustion with self-sustained acoustic excitation,” Tech. rep., REST, 2013.

[13] Vingert, L., Habiballah, M., Vuillermoz, P., and Zurbach, S., "MASCOTTE, a test facility for cryogenic combustion research at high pressure," 51st International Astronautical Congress, Rio de Janeiro, Brazil, 2000.

[14] Richecoeur, F., Scouflaire, P., Ducruix, S., and Candel, S., "High-Frequency Transverse Acoustic Coupling in a Multiple-Injector Cryogenic Combustor,” Journal of Propulsion and Power, Vol. 22, No. 4, 2006, pp. 790-799.

[15] Méry, Y., Ducruix, S., Scouflaire, P., and Candel, S., "Injection coupling with high amplitude transverse modes: Experimentation and simulation,” Compt. Rend. Mécan., Vol. 337, No. 6-7, 2009, pp. 426-437.

[16] Méry, Y., Hakim, L., Scouflaire, P., Vingert, L., Ducruix, S., and Candel, S., "Experimental investigation of cryogenic flame dynamics under transverse acoustic modulations," Comptes Rendus Mécanique, Vol. 341, No. 1-2, 2013, pp. 100-109.

[17] Richecoeur, F., "Expérimentations et simulations numériques des intéractions entre modes acoustiques transverses et flammes cryotechniques," Ph.D. thesis, Ecole Centrale de Paris, 2006.

[18] Méry, Y., "Mécanismes d'instabilités de combustion haute-fréquence et application aux moteurs-fusées,” Ph.D. thesis, Ecole Centrale Paris, 2010.

[19] Hakim, L., "Dynamics of transcritical coaxial flames in high-frequency transverse acoustic fields: application to liquid rocket engine instabilities," Ph.D. thesis, Ecole Centrale Paris, France, Febuary 2013.

[20] Méry, Y., "Impact of heat release global fluctuations and flame motion on transverse acoustic wave stability," Proceedings of the Combustion Institute, Vol. 36, No. 3, 2017, pp. 3889 - 3898. doi:https://doi.org/10.1016/j.proci.2016.08.009, URL http://www.sciencedirect.com/science/article/pii/S1540748916303984

[21] Marble, F. E., "Servo-Stabilization of Low-Frequency Oscillations in a Liquid Bipropellant Rocket Motor," Journal of the American Rocket Society, Vol. 23, No. 2, 1953, pp. 63-74. doi:10.2514/8.4542, URL http://dx.doi .org/10.2514/8.4542

[22] Crocco, L., and Cheng, S. I., Theory of combustion instability in liquid propellant rocket motors, Vol. Agardograph No 8, Butterworths Science, 1956. 
[23] Lores, M. E., and Zinn, B. T., "Nonlinear Longitudinal Combustion Instability in Rocket Motors," Combustion Science and Technology, Vol. 7, No. 6, 1973, pp. 245-256. doi:10.1080/00102207308952365.

[24] Culick, F. E. C., Unsteady Motions in Combustion Chambers for Propulsion Systems, RTO AGARDograph, Vol. RTO-AG-AVT039, The Research and Technology Organisation (RTO) of NATO, 2006.

[25] Poinsot, T., and Veynante, D., Theoretical and numerical combustion, R.T. Edwards, 2nd edition., 2005.

[26] Cheng, A. H.-D., and Cheng, D. T., "Heritage and early history of the boundary element method," Engineering Analysis with Boundary Elements, Vol. 29, No. 3, 2005, pp. 268 - 302. doi:https://doi.org/10.1016/j.enganabound.2004.12.001, URL http://wWw.sciencedirect.com/science/article/pii/S0955799705000020

[27] Tsien, H. S., “The transfer functions of rocket nozzles," Journal of the American Rocket Society, , No. May-June, 1952, pp. 139-143.

[28] Crocco, L., Supercritical Gaseous Discharge with High Frequency Oscillations, Defense Technical Information Center, 1952. URL https://books.google.fr/books?id=RhUlOAAACAA]

[29] Crocco, L., Monti, R., and Grey, J., "Verification of nozzle admittance theory by direct measurement of the admittance parameter," ARS Journal, Vol. 31, No. 6, 1961, pp. 771-775.

[30] Buffum, F. G., Dehority, L. G., Slates, R. O., and Price, E. W., "Acoustic losses of a subscale, cold-flow rocket motor for various 'J' values," Tech. rep., Bureau of Naval Weapons, 1966.

[31] Culick, F. E. C., and Dehority, G. L., "Analysis of acoustic waves in a cold-flow rocket." Journal of Spacecraft and Rockets, Vol. 6, No. 5, 1969, pp. 591-595. doi:10.2514/3.29618, URL http://dx.doi.org/10.2514/3.29618

[32] Nielsen, A. K., Acoustic Resonators of Circular Cross-Section and with Axial Symmetry, Danish Academy of Technical Sciences, 1949.

[33] Lambert, R. F., "A Study of the Factors Influencing the Damping of an Acoustical Cavity Resonator," The Journal of the Acoustical Society of America, Vol. 25, 1953, pp. 1068 - 1083.

[34] Searby, G., Habiballah, M., Nicole, A., and Laroche, E., "Prediction of the Efficiency of Acoustic Damping Cavities," Journal of Propulsion and Power, Vol. 24, No. 3, 2008, pp. 516-523. doi:10.2514/1.32325, URL http://dx.doi.org/10.2514/1. 32325

[35] Stokes, G. G., "On the Communication of Vibration from a Vibrating Body to a Surrounding Gas," Philosophical Transactions of the Royal Society of London, Vol. 158, 1868, pp. 447-463. URL http://www . jstor . org/stable/108920

[36] Kirchhoff, G., "Über den einfluss der wärmeleitung in einem Gase auf dis Schallbewegung," Annalen der Physik und Chemie, Vol. 210, 1868, pp. 177-193. 
[37] Tang, P., Harrje, D., and Sirignano, W., "Experimental verification of the energy dissipation mechanism in acoustic dampers," Journal of Sound and Vibration, Vol. 26, No. 2, 1973, pp. 263 - 276. doi:http://dx.doi.org/10.1016/S0022-460X(73)80235-4, URL http://www. sciencedirect.com/science/article/pii/S0022460X73802354

[38] Tong, A. Y., and Sirignano, W. A., "MULTICOMPONENT TRANSIENT DROPLET VAPORIZATION WITH INTERNAL CIRCULATION: INTEGRAL EQUATION FORMULATION AND APPROXIMATE SOLUTION," Numerical Heat Transfer, Vol. 10, No. 3, 1986, pp. 253-278. doi:10.1080/10407788608913519, URL http://dx.doi.org/10.1080/ 10407788608913519

[39] Oschwald, M., Farago, Z., Searby, G., and Cheuret, F., "Resonance Frequencies and Damping of a Combustor Acoustically Coupled to an Absorber," Journal of Propulsion and Power, Vol. 24, No. 3, 2008, pp. 524-533. doi:10.2514/1.32313, URL http://dx.doi.org/10.2514/1.32313

[40] Schuller, T., Durox, D., and Candel, S., "Self-induced combustion oscillations of laminar premixed flames stabilized on annular burners," Combustion and Flame, Vol. 135, No. 4, 2003, pp. 525 - 537. doi:10.1016/j.combustflame.2003.08.007, URL http://wwW.sciencedirect.com/science/article/pii/S0010218003002086

[41] Tang, P., and Sirignano, W., “Theory of a generalized Helmholtz resonator,” Journal of Sound and Vibration, Vol. 26, No. 2, 1973, pp. 247 - 262. doi:http://dx.doi.org/10.1016/S0022-460X(73)80234-2, URL http://www. sciencedirect.com/ science/article/pii/S0022460X73802342

[42] Culick, F. E. C., and Yang, V., “Overview of Combustion Instabilities in Liquid-Propellant Rocket Engines,” Liquid Rocket Engine Combustion Instability, Vol. 169, edited by V. Yang and W. E. Anderson, Washington, DC: AIAA, Inc, 1995 , pp. 3-37.

[43] Schuller, T., Durox, D., Palies, P., and Candel, S., "Acoustic decoupling of longitudinal modes in generic combustion systems," Combustion and Flame, Vol. 159, 2012, pp. 1921-1931.

[44] Klem, M. D., and Fry, R. S., "Guidelines for combustion stability specifications and verification procedures for liquid propellant rocket engines,” Tech. rep., CPIA Publication 655, January 1997.

[45] Lacaze, G., Cuenot, B., Poinsot, T., and Oschwald, M., "Large eddy simulation of laser ignition and compressible reacting flow in a rocket-like configuration," Combustion and Flame, Vol. 156, No. 6, 2009, pp. 1166 - 1180. doi:10.1016/j.combustflame. 2009.01.004, URL http://www.sciencedirect.com/science/article/pii/S0010218009000066

[46] Nicoud, F., Benoit, L., and Sensiau, C., "Acoustic Modes in Combustors with Complex Impedances and Multidimensional Active Flames," AIAA Journal, Vol. 45, 2007, pp. 426-441.

[47] Selle, L., Benoit, L., Poinsot, T., Nicoud, F., and Krebs, W., "Joint use of Compressible Large-Eddy Simulation and Helmoltz solvers for the analysis of rotating modes in an industrial swirled burner," comb. flame, Vol. 145, No. 1-2, 2006, pp. 194-205.

[48] Gonzalez-Flesca, M., "Simulation, experimentation and modeling contributions to the analysis of high frequency combustion instabilities in liquid propellant rocket-engines,” Ph.D. thesis, Ecole CentraleSupelec, France, November 2016. 
[49] Pons, L., Darabiha, N., and Candel, S., "Pressure effects on nonpremixed strained flames," Combustion and Flame, Vol. 152, No. 1-2, 2008, pp. 218 - 229. doi:http://dx.doi.org/10.1016/j.combustflame.2007.07.006, URL http://www. sciencedirect. com/science/article/pii/S0010218007001988

[50] Ribert, G., Zong, N., Yang, V., Pons, L., Darabiha, N., and Candel, S., "Counterflow diffusion flames of general fluids: Oxygen/hydrogen mixtures," Combust. Flame, Vol. 154, No. 3, 2008, pp. 319-330.

[51] Richecoeur, F., Ducruix, S., Scouflaire, P., and Candel, S., "Effect of temperature fluctuations on high frequency acoustic coupling," Proceedings of the Combustion Institute, Vol. 32, No. 2, 2009, pp. 1663 - 1670. doi:10.1016/j.proci.2008.05.068, URL http://wWW.sciencedirect.com/science/article/pii/S1540748908003143

[52] Lemmon, E., McLinden, M., and Friend, D., Thermophysical Properties of Fluid Systems, In the WebBook of Chemistry NIST, Standard Data Base NIST Number 69, Eds. P.J. Linstrom and W.G. Mallard, National Institute of Standards and Technology, Gaithersburg MD, 20899, http://webbook.nist.gov, 2012.

[53] Marble, F. E., and Candel, S., "Acoustic disturbances from gas nonuniformities convected through a nozzle," Journal of Sound and Vibration, Vol. 55, 1977, pp. 225-243.

[54] Schwing, J., Grimm, F., and Sattelmayer, T., "A Model for the Thermo-Acoustic Feedback of Transverse Acoustic Modes and Periodic Oscillations in Flame Position in Cylindrical Flame Tubes," ASME Turbo Expo 2012: Turbine Technical Conference and Exposition, Vol. 2, 2012. doi:http://dx.doi.org/10.1115/GT2012-68775.

[55] Gonzalez-Flesca, M., Schmitt, T., Ducruix, S., and Candel, S., "Large eddy simulations of a transcritical round jet submitted to transverse acoustic modulation,” Physics of Fluids, Vol. 28, 2016, p. 055106. 